\title{
NEM SEMPRE UM FILHOTE DE PÁSSARO FORA DO NINHO NECESSITA DE AJUDA
}

Vitor Leandro Lopes ${ }^{1}$

Cristina Oliveira Maia²

Resumo: $O$ crescimento dos centros urbanos vem causando inúmeras modificações dentro dos ecossistemas nos últimos anos, afetando assim a fauna e a flora que habitam estes ambientes. É recorrente o fato de pessoas encontrarem ninhos ou até mesmo filhotes de aves em ambiente de risco e desejarem salvar os indefesos levando-os para casa, interferindo no processo reprodutivo das aves. No intuito de amenizar este impacto, elaboramos e aplicamos um questionário onde identificamos os pontos de maior dificuldade da população. A partir das informações colhidas e dos estudos observando este tipo de comportamento, foi desenvolvida uma cartilha com informações sobre como lidar, de forma correta, com um filhote de pássaro ao encontrá-lo em lugar de risco, de acordo com sua idade e formação.

Palavras-chave: Avifauna; Meio Ambiente; Filhote; Reprodução.

1 Universidade Federal de Ouro Preto. E-mail: vitorleandrolopes@gmail.com

2 Universidade Federal de Ouro Preto. E-mail: maiacristina1@gmail.com

Revbea, São Paulo, V. 14, № 3: 252-259, 2019. 


\section{Introdução}

As aves compreendem o grupo de vertebrados mais facilmente reconhecível em função de suas características peculiares de coloração e período de atividade, predominantemente diurno (ANDRADE; ANDRADE, 2003). O Brasil possui a terceira avifauna mais rica do mundo, com mais de 1.800 espécies (CBRO, 2016). Considerando as ações de restrição à Educação Ambiental, uma vez que a atual política governamental dificulta a viabilização de projetos de incentivo à preservação, a simples observação da avifauna, segundo Costa (2007), da região torna-se uma excelente ferramenta para auxiliar na conservação da biodiversidade.

As justificativas para utilizar as aves são várias: elas apresentam distribuição cosmopolita, são abundantes mesmo nas maiores metrópoles, seu colorido e seu canto chamam a atenção e tornam prazerosa sua observação. A observação de aves na natureza tem se tornado uma atividade identificada como hobby e denominada Birdwatching, com início na Europa, no século XVIII (PIVATTO; SABINO, 2007).

O crescimento dos centros urbanos vem causando inúmeras modificações dentro dos ecossistemas nos últimos anos, afetando assim a fauna e a flora que habitam estes ambientes. Devido a essas modificações, animais selvagens têm sido encontrados em maior número nas cidades, aumentando a chance de contato com os humanos e a criação de vínculo, modificando os hábitos alimentares e reprodutivos destes animais. Na maioria dos hábitats antropizados, onde se incluem as cidades, as aves convivem pacificamente e em harmonia com o homem, seja em áreas urbanas ou periurbanas.

As aves interagem ativamente com o meio ambiente, desempenhando grandes papeis dentro do ecossistema. A polinização de diversas espécies, dispersão de inúmeras sementes e controle de insetos que podem vir a se tornar abundantes na população são alguns exemplos (ANDRADE; ANDRADE, 2003).

Os centros urbanos são locais propícios para reprodução das aves (CARVALHO et al., 2008), visto que diversos predadores silvestres não têm acesso (ICMBIO, 2011) às estruturas desenvolvidas pelos humanos, resguardando as aves. Nestas áreas encontramos compartimentos que são excelentes para reprodução, como os telhados, canos, estruturas de coberturas, locais que não seriam possíveis dentro de matas. Para completar o ciclo das aves, é desejável que as mesmas se reproduzam no intuito de perpetuar a espécie, portanto o ambiente urbano pode ser bastante favorável.

Por outro lado, por estarem inseridas em centros urbanos, as pessoas acabam interferindo no processo reprodutivo das aves. Embora na maioria das vezes o indivíduo interfira no intuito de colaborar para sobrevivência, eventualmente encontrando um filhote fora do ninho, por falta de informação, acaba impactando negativamente no ciclo das aves. Encontrar um filhote de 
ave indefeso caído é uma das atividades mais comoventes para os amantes da natureza. Pois bem, é recorrente o fato de pessoas encontrarem ninhos ou até mesmo filhotes em ambiente de risco e desejarem salvar os indefesos, levando-os para casa. Porém, este pode ser um processo mais complicado do que parece (GROSMANN, 2018).

A maior dificuldade de atendimento do Centro de Triagem de Animais Silvestres (CETAS), é que a população humana tem interferido nos processos naturais de aprendizagem das aves. Quando elas estão em seu primeiro voo e necessitam de treinamento, a população aprisiona os filhotes, por achar que ele é indefeso e acaba prejudicando o desenvolvimento biológico da ave. Essas situações podem reduzir o número de espécies na natureza, podendo levar à extinção de espécies em massa. Sendo assim, faz-se necessário confeccionar um material de divulgação para que pessoas leigas possam contribuir de forma eficaz para conservação das espécies de aves nos centros urbanos.

Elaboramos e aplicamos um questionário, com o objetivo de identificar os pontos de maior dificuldade da população. A partir das informações colhidas e dos estudos observando este tipo de comportamento, foi desenvolvida uma cartilha com informações sobre como lidar, de forma correta, com um filhote de pássaro, ao encontrá-lo em lugar de risco, de acordo com sua idade e formação.

\section{Métodos}

Foi elaborado um formulário contendo informações referentes à biologia reprodutiva das aves e como não influenciar neste processo para que a ave tenha sucesso reprodutivo. A coleta de dados preliminares foi realizada por meio de um questionário estruturado, distribuído online, não exigindo a presença do pesquisador e permitindo alcançar muitas pessoas, por um custo baixo e abrangendo uma ampla área geográfica (BONI, QUARESMA, 2005).

O método consistiu no desenvolvimento e ampla divulgação de um web survey, ou seja, realizamos coleta de dados de uma amostra representativa de população diversificada, realizada em ambiente online (CARNEIRO, DIB, 2011). O questionário contém uma pergunta aberta para identificar a localidade do participante e diversas perguntas objetivas, estas últimas oferecendo alternativas de resposta. Foi disponibilizado através do Google Forms, constituinte da suíte Google Drive, e funciona como web host tanto para o formulário quanto para a base de dados que armazena as respostas. O formulário foi amplamente divulgado, para pessoas de diversas localidades e com diferentes níveis de ensino no intuito de ter uma amostragem significativa da população. No formulário apresentamos algumas informações sobre determinadas situações, esclarecendo como lidar e como favorecer o sucesso reprodutivo das aves. 


\section{Resultados e discussão}

- Interações

O questionário ficou disponível durante 20 dias, no mês de novembro de 2018 , sendo respondido por 158 pessoas, oriundas de 13 estados distintos e 56 cidades diversas. A heterogeneidade dos participantes favoreceu que a amostragem não fosse tendenciada a um grupo próximo aos pesquisadores.

\section{- Faixa etária e sexo}

Dentre as pessoas que colaboraram respondendo o questionário 59 $(37,3 \%)$ apresentaram idades entre 20 e 25 anos, 28 (17,7\%) com idade entre 25 e 30 anos, 21 (13,3\%) com idade entre 10 e 20 anos, 19 (12\%) com idade entre 30 e 40 anos, $18(11,4 \%)$ com idades entre 40 e 50 anos e por fim 13 $(8,2 \%)$ com idade acima de 50 anos. Para o quesito sexo, tivemos 91 mulheres que corresponde a $57,6 \%$ dos participantes e 67 homens, com $42,4 \%$ das contribuições.

\section{- Escolaridade}

O nível de escolaridade dos colaboradores foi bem diverso, pessoas com o ensino médio completo contabilizaram 67 indivíduos $(42,4 \%)$, as pessoas que possuem ensino superior em qualquer área do conhecimento somaram $61(38,6 \%)$, pessoas que possuem mestrado, $19(12 \%)$, contamos com participação de nove (9) doutores $(5,7 \%)$ e duas (2) pessoas com ensino fundamental $(1,3 \%)$. A participação de pessoas de diferentes níveis de instrução é de extrema importância, uma vez que havia intenção de alcançar todos os estratos da população, informando sobre a preservação das aves.

\section{- Contato com aves}

Grande parte dos participantes declarou possuir uma certa afinidade com aves, 100 (63,3\%), mostrando o quão importante este grupo pode ser para Educação Ambiental. Nenhum participante demostrou ornitofobia e apenas 10 indivíduos $(6,3 \%)$ declararam não possuir afinidade com estes animais. O interesse apresentado pelas pessoas por este grupo animal pode ser uma grande ferramenta no processo educacional.

Dentre os participantes, $27(17,1 \%)$ possuem aves em suas residências e demais $21(13,3 \%)$ demonstraram ter algum contato no ambiente onde vivem, contribuindo para uma melhor qualidade de vida e do meio ambiente.

\section{- Encontro com filhote de pássaros}

A grande maioria dos participantes, 135 (85,4\%), em algum momento de suas vidas já encontrou com filhotes de aves fora do ninho. Quando as aves estão treinando seus voos é comum elas ficarem fora do ninho, muitas das 
vezes sendo resgatadas ou deslocadas por pessoas que, no intuito de ajudar, acabam atrapalhando o processo biológico delas. Apenas 23 (14,6\%) declararam nunca ter encontrado um filhote caído fora do ninho.

\section{- Tentativa de contribuir para o sucesso dos filhotes}

$\mathrm{Na}$ tentativa de contribuir para o sucesso na vida dos pássaros, 57 indivíduos $(36,1 \%)$ levaram os mesmos para suas respectivas residências no intuito de oferecer abrigo e alimento aos animais. O problema desta intervenção é que as aves têm seu desenvolvimento influenciado e acabam ficando dependentes dos humanos, inviabilizando ou dificultando seu retorno à natureza. Muitas das vezes será indispensável que a ave passe por um processo de reintrodução, onde monitora-se os hábitos alimentares até obter a independência necessária.

Dentre os outros que responderam ao formulário, 37 pessoas $(23,4 \%)$ tiveram sucesso no processo de retorno dos filhotes aos seus ninhos e 28 $(17,7 \%)$ deixaram os filhotes no mesmo lugar, para não influenciar na biologia das aves. Por fim, $36(22,8 \%)$ participantes da pesquisa não encontraram com filhotes fora do ninho ou tiveram qualquer outra relação, como encontrar com filhote morto.

\section{- Sucesso do filhote}

Uma parcela dos participantes, 59 (37,3\%), não levou os filhotes encontrados para casa, contribuindo ativamente para o sucesso deles na natureza. Já $55(34,8 \%)$ indivíduos tiveram sucesso e conseguiram que os filhotes retornassem à natureza, $32(20,3 \%)$ declararam o óbito dos filhotes resgatados, mostrando o quão é importante divulgar informações referentes ao processo reprodutivo das aves, para evitar que as pessoas interfiram nos mesmos.

\section{- Filhote na fase de ninhego}

Esta fase é bem crítica, quando os filhotes estão no ninho e desprovidos de penas de cobertura. Respondendo sobre esta fase, 60 (38\%) pessoas teriam atitude de colocar o mesmo no ninho ou improvisar um ninho em local seguro, contribuindo ativamente para sobrevivência deles. Do total de 158 pessoas que responderam, $49(31,1 \%)$ consideram que não deveriam colocar as mãos no filhote, pois o odor afastaria os pais. Estes acreditam que, uma vez que o filhote se encontre em local de risco, é melhor tentar pegar o mesmo com auxílio de algum material, quando não possível usar as próprias mãos para assegurar a sobrevivência deles. Outros $28(17,7 \%)$ levariam ao centro de triagens de animais silvestres (CETAS), que é o órgão responsável por receber animais em situações de vulnerabilidade e $18(11,4 \%)$ levariam o filhote para casa. 


\section{- Filhote na fase juvenil}

Esta é a fase em que os pássaros jovens estão descobrindo o mundo e treinando suas habilidades de voo. Neste período, 85 (53,8\%) dos participantes deixariam as aves no mesmo local, sendo esta a ação perfeita para o desenvolvimento das aves e $46(29,1 \%)$ improvisariam um ninho para fornecer um ambiente seguro. Nesta fase esse procedimento é dispensado, pois ela vai evadir do local providenciado para treinar novamente 0 voo. Dentre os que responderam, $15(9,5 \%)$ levariam o filhote para casa, o que não é uma atitude eficaz, quando a ave se encontra visivelmente em perfeito estado. E por fim, 12 $(7,5 \%)$ entregaria no CETAS, que é um outro problema, visto que as aves vão ter que passar por um processo de reintrodução, causando gastos que poderiam ser direcionados a outros procedimentos mais complicados.

\section{- Importância do questionário para Educação Ambiental}

A aplicação deste questionário foi de grande importância. Considerando as respostas obtidas, foi possível identificar o ponto de maior dificuldade da população amostrada. Junto às perguntas, algumas informações relevantes ao processo reprodutivo e como lidar com situações que apresentam algum risco aos filhotes foram levadas aos participantes. A Educação Ambiental por meio dos pássaros é de extrema importância, considerando que eles atuam em diversos aspectos nos ecossistemas, como polinizadores e dispersores, entre outros. Assim, uma vez que a diversidade e a abundância das espécies são reduzidas, a diminuição desses serviços prestados pelas mesmas pode causar uma desestabilização, impactando diretamente na quantidade de alimento produzido, modificando a disponibilidade.

\section{-Confecção da cartilha}

Após o processo análise do questionário, nota-se claramente que algumas pessoas apresentaram dificuldade em lidar com um filhote de pássaro encontrado fora do ninho, em todas as fases de desenvolvimento da ave. Para tentar amenizar o impacto e a intervenção de forma equivocada, foi elaborada uma cartilha esquematizada em formato de fluxograma, para auxiliar as pessoas leigas sobre como agir quando encontrarem filhotes indefesos (Figura 1). 


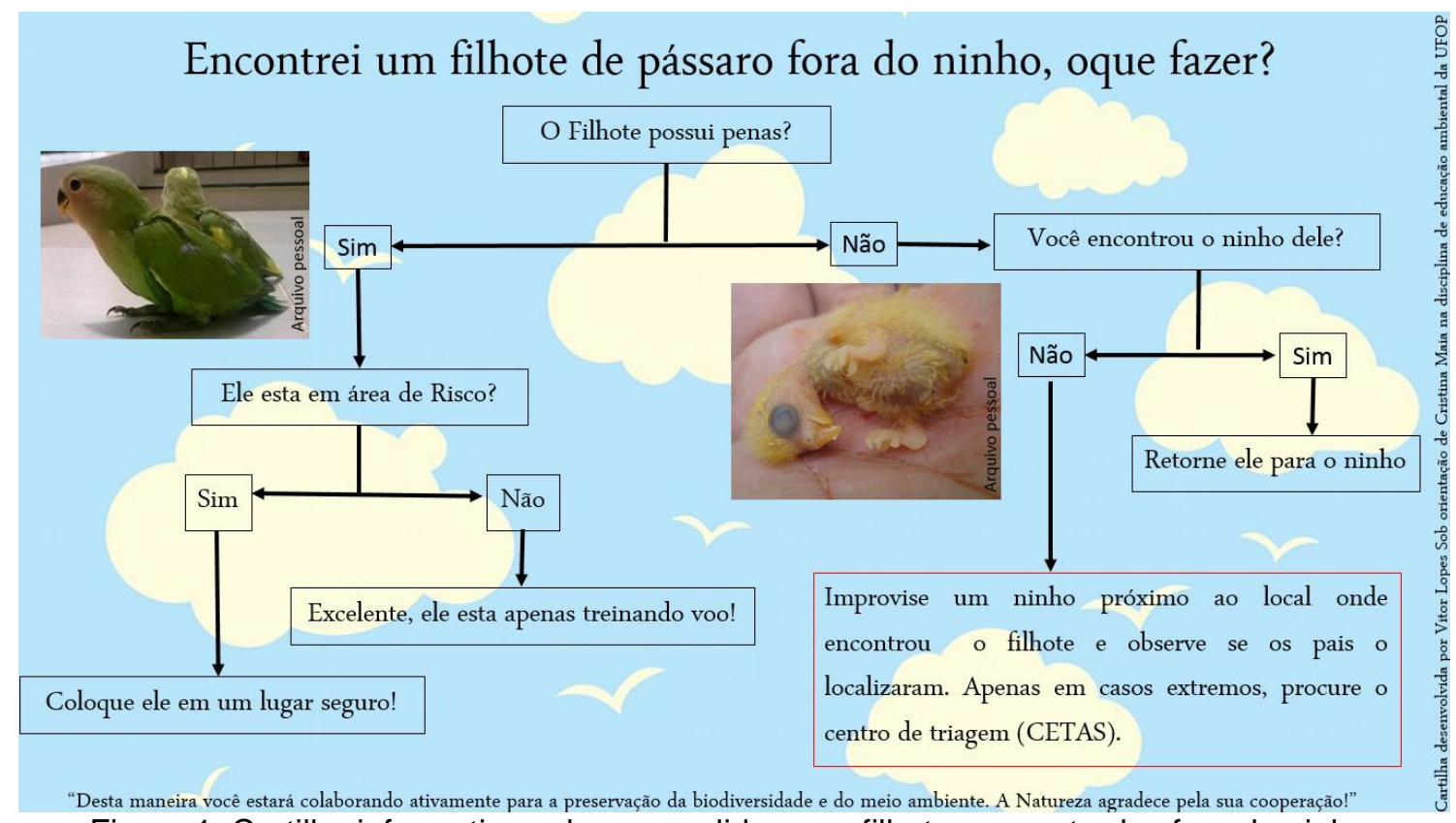

Figura 1: Cartilha informativa sobre como lidar com filhotes encontrados fora do ninho.

\section{Conclusões}

A Educação Ambiental é de extrema importância e a relação com os pássaros se apresenta como excelente ferramenta para auxiliar neste processo. Conforme observamos nas respostas, uma grande parte dos participantes apresentam afinidade por esse grupo de animais. Por meio do uso deste questionário foi possível identificar que é recorrente a intervenção das pessoas nos hábitos reprodutivos das aves, o que levou à produção de uma cartilha informativa. Os dados mostram a dificuldade que muitas pessoas apresentam quando colocadas frente a essa situação, indicando que devemos trabalhar ativamente para tentarmos reverter esse quadro, contribuindo para biodiversidade e o meio ambiente, mantendo as funções de cada organismo dentro do ecossistema.

\section{Agradecimentos}

Agradeço ao Departamento de Biodiversidade Evolução e Meio Ambiente da Universidade Federal de Ouro Preto e a todos professores que contribuíram de alguma forma, seja transmitindo conhecimento, espalhando o questionário. Agradeço cada um que teve disponibilidade em responder 0 questionário contribuindo ativamente para elaboração do trabalho. 


\section{Referências}

ANDRADE, M.A.; ANDRADE, M.V.G. Portraits of brazilian birds - Retratos de aves brasileiras. Belo Horizonte: Editora Líttera Maciel, 2003. 128p.

BONI V.; QUARESMA, S.J. Aprendendo a entrevistar: como fazer entrevistas em Ciências Sociais. Em Tese v. 2, n. 1, pp. 68-80. 2005.

CARNEIRO, J.M.T.; DIB, L.A.R. O uso da internet em surveys: oportunidades e desafios. Administração: Ensino e Pesquisa v. 12, n. 4, pp. 641-670. 2011.

CARVALHO-FILHO, E.P.M.; CARVALHO, C.E.A.; CARVALHO, G.D.M. Descrição da nidificação de Micrastur semitorquatus (Falconiformes: Falconidae) no interior de uma habitação rural, no município de Sete LagoasMG. Atualidades Ornitológicas, n. 86, p. 12, 1998.

COMITÊ BRASILEIRO DE REGISTROS ORNITOLÓGICOS - CBRO. Lista das aves do Brasil. 11 $1^{\text {a }}$ edição. Sociedade Brasileira de Ornitologia. 2016. Disponível em: <http://www.cbro.org.br/CBRO/listabr.htm> Acesso em (22/11/2018).

COSTA, R.G.A. Observação de aves como ferramenta didática: algumas considerações pedagógicas. Atualidades Ornitológicas n. 137, pp. 4-7. 2007.

GROSMANN, A.F.; FERRERA, T.S. A Educação Ambiental através de observações de aves. Anais do SEPE - Seminário de Ensino, Pesquisa e Extensão da UFFS, [S.I.], v. 6, n. 1. 2018. ISSN 2317-7489.

ICMBIO. Predadores silvestres e animais domésticos. Guia prático de convivência. Instituto Chico Mendes de Conservação da Biodiversidade. 2011.

PIVATTO, M.A.; SABINO, J. O turismo de observação de aves no Brasil: breve revisão bibliográfica e novas perspectivas. Atualidades Ornitológicas n. 139, pp. 10-13. 2007. 